\title{
Late presentation of a solitary metastasis of renal cell carcinoma as an obstructive duodenal mass
}

\author{
SKC Toh, JE Hale
}

\begin{abstract}
Summary
We present a rare case of late solitary metastasis of renal cell carcinoma presenting with duodenal obstruction. Metastatectomy resulted in relief of symptoms and may improve long-term survival.
\end{abstract}

Keywords: renal cell carcinoma, metastasis, duodenal obstruction

Renal cell carcinoma rarely metastasises to the small intestine; the least frequent site being the duodenum. Complications from metastasis to the duodenum include acute and chronic gastrointestinal bleeding, malabsorption, and obstructive jaundice. Although perforation and intestinal obstruction have been reported from metastases to the gastrointestinal tract, the late presentation of an unusual solitary metastasis from renal cell carcinoma to the fourth part of the duodenum has not been documented. We report such a case and present a review of the literature.

\section{Case report}

A 59-year-old woman underwent a left radical nephrectomy with splenectomy for Stage 1 renal cell carcinoma. She remained well without further treatment until 10 years later, when she presented with lethargy, collicky abdominal pains, indigestion, anorexia and weight loss. She was already on oral iron therapy for iron deficiency anaemia discovered six months previously when oesophago-gastro-duodenoscopy, barium enema and colonoscopy failed to elicit a cause for her anaemia. No abdominal mass was palpable on physical examination. However, ultrasound scan of the abdomen revealed an epigastric mass, and computed tomography (CT) suggested a solid mass below and separate from the pancreas, adherent to the small bowel. A CT-guided biopsy of the mass was inconclusive. She subsequently deteriorated rapidly, and began to vomit postprandially, requiring parenteral nutrition. She was referred to the surgeons who suspected gastric outflow obstruction. At laparotomy, there was no evidence of liver or nodal metastasis, but the proximal duodenum and stomach were grossly distended due to an intraluminal mass within the fourth part of the duodenum. A duodenotomy was performed through this, and with digital examination, the mass was found to be pedunculated, being attached by a wide stalk to the posterior wall of the duodenum (figure). The incision was extended and the stalk transfixed, the mass excised, and the duodenotomy closed. She made a good recovery and was able to eat and drink on discharge 13 days post-operation. Six months later, she remained well and had gained weight.

The histology revealed a polypoidal mass arising from the serosa of the duodenum consisting of granulation tissue with chronic inflammatory cells and clusters of polyhidral cells with clear cytoplasm, some coming close to but not involving the resection margin of the stalk. The histology puzzled the pathologists until they were made aware of the previous renal cell carcinoma. This was not mentioned to them initially as it was not thought to be clinically relevant in view of the radical surgery and favourable prognosis of the Stage 1 tumour and the length of time that had transpired. Immunohistological stains confirmed these cells to be clear cell carcinoma similar to those seen in the original tumour.

\section{Discussion}

The lung and bone are the commonest sites for metastasis from renal cell carcinoma. Other common sites are lymph node, adrenal, liver, opposite kidney, and brain. Only 4\% metastasise to the small intestine, ${ }^{1}$ although of the $2 \%$ of all metastatic tumours that do involve the small intestine, $7.1 \%$ are from renal cell carcinoma. ${ }^{2}$ Of these, the duodenum is the least frequent site and can be involved by direct invasion of the tumour, or through lymphatic, transcoelomic or haematogenous spread., ${ }^{3,4}$ Of the several case reports of duodenal and proximal ileal metastases, some have presented more

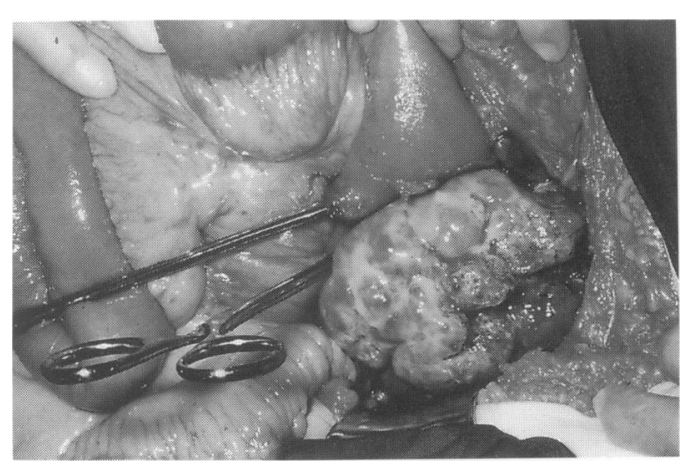

Figure Duodenotomy revealing pedunculated tumour 
Table Case reports of late metastases of renal cell carcinoma to the duodenum and jejunum (only (5) is a case of solitary metastasis)

\begin{tabular}{|c|c|c|c|c|c|c|c|}
\hline Ref no & Age/sex & Stage & $\begin{array}{l}\text { Interval } \\
\text { operation to } 2^{\circ} \\
\text { (years) }\end{array}$ & Presentation & Site & Surgery & $\begin{array}{l}\text { Survival } \\
\text { (months) }\end{array}$ \\
\hline 5 & $70 / \mathrm{M}$ & 2 & 12 & GI bleed & ampulla & Whipple's & - \\
\hline 8 & $-/ \mathbf{F}$ & 1 & 10 & - & duodenum & - & 18 \\
\hline 8 & $-/ M$ & 2 & 16 & - & duodenum & - & 5 \\
\hline 4 & $71 / \mathrm{M}$ & - & 11 & GI bleed & $\begin{array}{l}\text { prox. ileum } \\
\left(\text { liver } 2^{\circ}\right)\end{array}$ & excision & 1 \\
\hline 6 & $52 / \mathrm{M}$ & $1 B$ & 10 & malabsorption & $\begin{array}{l}\text { ampulla } \\
\left(\text { nodal } 2^{\circ}\right)\end{array}$ & diagnostic only & - \\
\hline
\end{tabular}

than 10 years following nephrectomy (table). Long dormancy is a notable feature of renal cell carcinoma, with $11 \%$ of patients surviving more than 10 years having late recurrences. ${ }^{5}$ The mechanisms underlying tumour dormancy are unknown, although a possible hypothesis is the breakdown of host homeostatic mechanisms which would otherwise hold in check the growth of micrometastases. ${ }^{6}$

This case is instructive in several ways. Firstly, it reminds clinicians that renal cell carcinoma can metastasise late and to unusual sites. Secondly, the cause of her iron deficiency anaemia was chronic bleeding from the tumour which was missed on conventional endoscopy. The evaluation of the small bowel with contrast studies or preferably, using the recently introduced enteroscope should be considered as part of the assessment of patients with suspected gastrointestinal bleeding. ${ }^{7}$ We plan to followup this patient in this manner to look for further recurrences within the small intestine, in addition to CT. Thirdly, although the surgery was undertaken for symptoms, there was no evidence of other metastases clinically, radiologically or at laparotomy. The incidence of apparently solitary metastasis has been reported to be $1 \%$ to $3 \%$, although in these

1 Grahm AP. Malignancy of the kidney, survey of 195 cases. $\mathcal{f}$ Urol 1947; 58: 10 .

2 Willis RA. Secondary tumors of the intestine. The spread of tumors in the human body, 3rd edn. London: Butterworth \& tumors in the human body

3 Lynch-Nyhan A, Fishman EK, Kadir S. Diagnosis and management of massive gastrointestinal bleeding owing to duodenal metastasis from renal cell carcinoma. $\mathcal{F}$ Urol 1987; 138: $611-3$.

4 Mackenzie JW. Recurrent obscure small-bowel haemorrhage due to metastatic renal carcinoma. Br $\mathcal{F}$ Hosp Med 1985; 34: 236.

5 Robertson GS, Gertler SL. Late presentation of metastatic renal cell carcinoma as a bleeding ampullary mass. Gastrointest Endosc 1990; 36: 304-6.

Learning points
- renal cell carcinoma can metastasise late and
to unusual sites
- 1 to $3 \%$ are apparently solitary metastases
- metastatectomy may relieve symptoms and
improve survival and should be considered
where possible
investigation of the small bowel using imaging
and enteroscopy should be considered in
suspected gastrointestinal bleeding when
findings are negative on conventional
endoscopy

patients, the prospects of further metastases are high, being 10 out of 19 cases in one series. ${ }^{8}$ Metastatectomy can result in a five-year actuarial survival rate of $31 \%$ to $35 \%$ which compares favourably with the known five-year actuarial survival of $13 \%$ to $17 \%$ in nephrectomised patients with metastatic disease. ${ }^{1,8,9}$ Finally, with regard to adjuvant treatment, the current evidence suggests that hormonal therapy, chemotherapy and immunotherapy do not significantly improve survival, although the latter is currently being evaluated in prospective clinical trials. ${ }^{10}$

6 McNichols DW, Segura JW, De Weerd JH. Renal cell carcinoma in long-term survival and late recurrence. $\mathcal{f}$ Urol 1981; 126: 17-23.

7 McKenna JI, Kozarek RA. Metastatic hypernephroma to 7 McKenna JI, Kozarek RA. Metastatic hypernephroma to the ampulla of Vater: An unusual cause of malabsorption roenterol 1989; 84: 81-3.

8 Tolia BM, Whitmore WF. Solitary metastases from renal cell carcinoma. F Urol 1975; 114: 836-8.

9 Pizzocaro G, Piva L, Mapelli S, Zucchi V. Surgical treatment of distant metastases in renal cell carcinoma. Arch Ital Urol Nefrol Androl 1991; 63: 245-8. 10 Olsson CA. Kidney tumors. Urol Clin N Am 1993; 20: 